\section{puente de Champlain}

\section{R. H. WOLFSBERGER, ingeniero}

562.62

\section{Introducción}

Esta importante obra, de unos $6 \mathrm{~km}$ de longitud, subdividida en tres trozos, unirá la ciudad de Montreal con la margen sur del río San Lorenzo. El trozo objeto de esta descripción dispone de una estructura de hormigón, de tramos múltiples, rectos, sobre pilas, salvados con vigas de hormigón pretensado prefabricadas en talleres instalados en lugares próximos a los de las posiciones que de forma definitiva han de ocupar.

El trozo tiene $457 \mathrm{~m}$ de longitud, 12 tramos rectos, salvados con 11 vigas de hormigón pretensado, de $39 \mathrm{~m}$ de longitud, que soportan un tablero de $27,5 \mathrm{~m}$ de anchura, dando cabida a seis bandas de circulación.

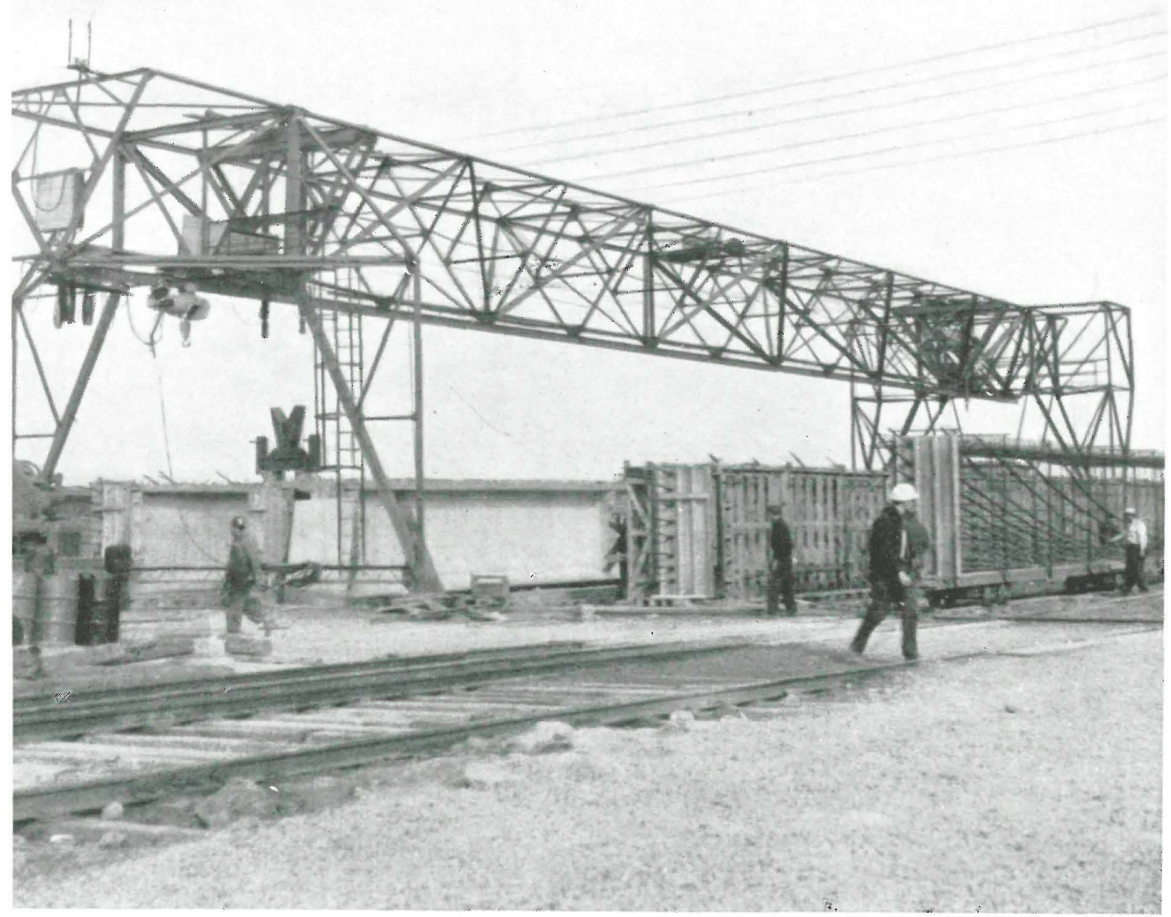

\section{Las vigas}

Las vigas pretensadas de esta estructura se apoyan sobre pilas de hormigón que descansan sobre roca firme.

Estas vigas tienen una longitud de 39 metros, $215 \mathrm{~m}$ de canto formando $\mathrm{T}$ de 1,30 m entre extremidades del ala superior, alma de $15 \mathrm{~cm}$ de espesor y cabeza inferior de $0,70 \mathrm{~m}$ de anchura.

Las armaduras de cada una de las 132 vigas se componen de 12 cables de 12 alambres de $7 \mathrm{~mm}$ de diámetro, debidamente anclados en bloques de cabeza siguiendo los procedimientos Freyssinet. Aparte de estas armaduras, las vigas tienen otras de tipo ordinario formando estribos. Una vez terminada, la viga pesa 80 t, y su hormigón tiene una resistencia de $350 \mathrm{~kg} / \mathrm{cm}^{2}$.

\section{Taller de prefabricación de vigas}

Las vigas se hormigonaron en un taller de prefabricación que, debido a la dificultad de hallar una superficie disponible próxima, se habilitó a unos $420 \mathrm{~m}$ de la obra una plataforma ampliada con un entramado adicional de madera. 


\section{construcción y lanzamiento}

Este taller, equipado con una grúa pórtico móvil, encofrados de madera revestidos con chapa de acero, logró un rendimiento de dos vigas por día, que resultó bajo, por no disponer de bloques de anclaje previamente preparados, ya que las vigas no podían tesarse antes de alcanzar el hormigón una resistencia mínima de $340 \mathrm{~kg} / \mathrm{cm}^{2}$.

El transporte del taller a la obra se realizó por medio de mesillas montadas sobre una vía previamente construída. Las mesillas se utilizaban posteriormente para el transporte del hormigón durante la construcción de la losa del tablero del puente.

\section{Puente de montaje}

Para la colocación de las vigas en su posición definitiva se preparó un puente auxiliar, metálico, en celosía, dotado de un dispositivo que permitía el ajuste y colocación exacta de cada viga sobre sus soportes.

Este puente móvil auxiliar, clave en la construcción del puente, ha sido el elemento esencial del que ha derivado todo el proceso de un método constructivo en el que la repetición ha sido monótona y de alto rendimiento económico, permitiendo, a su vez, reducir notablemente en número la mano de obra.

Las mesillas utilizadas para el transporte de las vigas desde el taller de prefabricación a la obra, se utilizaban también para ir avanzando el puente móvil de montaje a medida que se iban terminando cada uno de los tramos. Este puente, de $58 \mathrm{~m}$ de longitud y 100 t de capacidad, se corría sobre mesillas que deslizaban sobre vías tendidas apoyándose en los soportes o pilas del puente.

\section{Pilas}

Los soportes del puente están constituídos por pilas macizas, cuyos cabezales vuelan a uno y otro lado del fuste o cuerpo de la pila. En la parte superior de este cabezal se han formado unos dados de apoyo, uno para cada pila, convenientemente espaciados y sobre los que se colocaron almohadillas de neopreno como asiento directo de la cabeza inferior de cada una de las vigas.
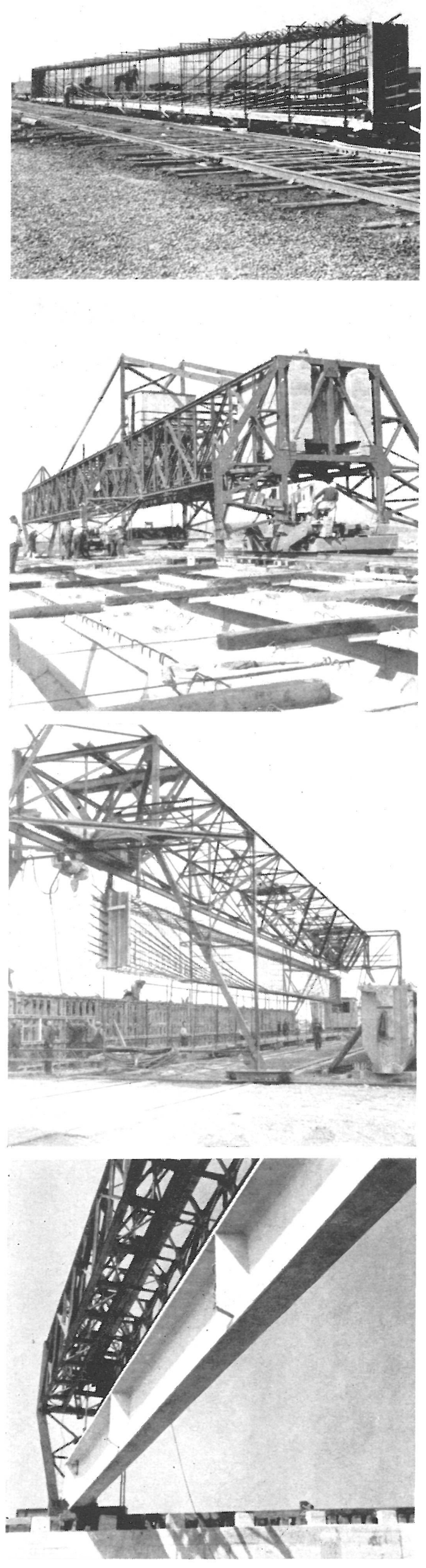